Article

\title{
Age-Standardized Breast Cancer Detection Rates of Breast Cancer Screening Program by Age Group in Korea; Comparison with Age-Standardized Incidence Rates from the Korea Central Cancer Registry
}

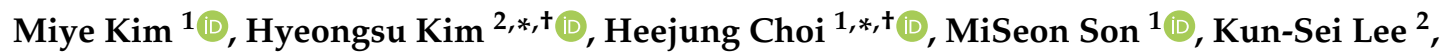 \\ Tae-Hwa Han ${ }^{3}$ and Sollip Kim ${ }^{4}$ (D) \\ 1 Department of Nursing, Graduate School, Konkuk University, Chungju 27478, Korea; \\ evanesel@naver.com (M.K.); mi-sun626@hanmail.net (M.S.) \\ 2 Department of Preventive Medicine, School of Medicine, Konkuk University, Seoul 05029, Korea; \\ kunsei.lee@kku.ac.kr \\ 3 Health-IT Center, College of Medicine, Yonsei University, Seoul 03722, Korea; taehwa.han@gmail.com \\ 4 Department of Laboratory Medicine, Inje University, Ilsan Paik Hospital, Goyang 10380, Korea; \\ lalacopine@gmail.com \\ * Correspondence: mubul@kku.ac.kr (H.K.); hjchoi98@kku.ac.kr (H.C.); \\ Tel.: +82-2-2030-7942 (H.K.); +82-43-840-3954 (H.C.) \\ + Both authors contributed equally to this work.
}

Received: 31 March 2020; Accepted: 8 May 2020; Published: 11 May 2020

\begin{abstract}
To compare the epidemiological characteristics of a breast cancer screening program of patients between $40-69$ years of age and $\geq 70$ years of age, we calculated the age-standardized detection rate of the breast cancer screening program and compared it with the age-standardized incidence rate from the Korea Central Cancer Registry. The data of the breast cancer screening program from January 2009 to December 2016 and the data of the health insurance claims from January 2006 to August 2017 were used. In the 40-69 year age group, the age-standardized detection rate of breast cancer increased annually from 106.1 in 2009 to 158.6 in 2015 and did not differ from the age-standardized incidence rate. In the $\geq 70$ year age group, the age-standardized detection rate of breast cancer increased annually from 65.7 in 2009 to 120.3 in 2015 and was 1.9 to 2.7 fold of the age-standardized incidence rate. It shows that the early detection effect of breast cancer screening was greater for patients over 70 years old. Further studies are needed to evaluate the effect of breast cancer detection in the $\geq 70$ year age group on all-cause mortality or breast cancer mortality.
\end{abstract}

Keywords: breast cancer; screening; incidence rate; detection rate

\section{Introduction}

Affecting 1.7 million women each year, breast cancer is the most common women's cancer worldwide. Furthermore, it is also the only type of women's cancer where its rates are increasing [1]. Recently, Korea discovered a significant change in breast cancer incidence and death aspects due to the rapid westernization of Korean diets over the last 20 years [2]. According to the Korean cancer statistics, breast cancer is the second most common cancer after thyroid cancer, with the incidence and mortality rate continuing to rise [3]. That is, the age-standardized incidence rate of breast cancer in Korea rose from 14.5 per 100,000 women in 1993 to 62.5 in 2016, and the age-standardized death rate from breast cancer increased from 3.7 per 100,000 women in 1993 to 7.0 in 2017 [4-7]. Age-specific incidences showed peaks in women in their forties. This is causing a steady increase in the individual and social cost burden associated with breast cancer treatment [8]. 
To reduce the social costs associated with cancer, many countries have adopted screening test-programs which promote early detection and early treatment. Mammography screening is one of the screening test-programs which is specific to breast cancer [9]. Despite the limitation of false positive diagnosis, many studies have reported that mammography screening has reduced breast cancer mortality rates, as early diagnosis has allowed efficient treatment and prevention [10,11]. Consequently, in 1999 Korea also began conducting breast cancer screening on women aged 40 or older every two years [9]. Recently, in terms of compatibility with mammography screening, each country issued recommendations that include the age and cycle recommendations and the level of evidence for breast cancer screening [12-15]. The National Cancer Center in Korea also announced a revision of the new breast cancer screening recommendations that include age and cycle [6]. The proposed revisions are categorized according to age and should be conducted every two years (recommendation grade B) for women aged 40-69 and asymptomatic. In the case of 70 years of age or older, it is recommended to selectively perform breast cancer screening using mammography (recommendation grade $\mathrm{C}$ ) in consideration of individual risk and evaluation [9]. In the development process of new breast cancer screening recommendations, only one domestic paper was used [16]. In addition, there have been few studies dealing with the difference in the effectiveness of breast cancer screening programs by age group, used in the recommendation.

In this study, we aimed to compare the differences in epidemiological characteristics on breast cancer screening programs between two age groups. Especially, the age-standardized breast cancer detection rate of the breast cancer screening program was compared with the age-standardized incidence rate from the Korea Central Cancer Registry (KCCR) in order to discuss how we have to consider age factor, in view of the trend of detection rate, in determining the upper age limit for breast cancer screening.

\section{Materials and Methods}

\subsection{Data Sources and Study Design}

In this study, two data set of the National Health Insurance Service (NHIS) were used; (1) The data of the breast cancer screening program from January 2009 to December 2016 and (2) the data of health insurance claims from January 2006 to August 2017. This study used a secondary data analysis to compare cancer detections within 6 months from the time of screening by dividing the breast cancer screening participants into the age groups of 40-69 years and 70 years and older.

\subsection{Study Subjects}

The subjects screening results were classified as normal, benign lesion, suspected breast cancer, and deferred. Suspected and deferred breast cancer diagnoses were defined as positive screening outcomes. The subjects were limited to participants in breast cancer screening not diagnosed with breast cancer. Screening participants who made insurance claims for the code for breast cancer (C50) and the code for special case (V193) from 1 January 2006, until the day of breast cancer screening were excluded. The code for special case aimed to ameliorate the economic burden on patients with cancer, cerebrovascular or cardiovascular disease, severe burns, or other intractable disease by reducing the copayment for 5 years [17].

\subsection{Variables}

The subjects' identification, age, screening date, result notification date, and screening results were obtained from the breast cancer screening data and the subjects' identification, sex, breast cancer diagnostic code, code for special case, and dates of visits to medical institutions from the insurance claims data. The subjects were categorized according to age at the time of screening into the 40-69 year age group or the $\geq 70$ year age group. The results of breast cancer screening were classified as 'normal', 'benign lesion', or 'suspected breast cancer'. A finding of 'normal' or 'benign lesion' was categorized as 
a negative result; a finding of 'suspected breast cancer' was considered a positive result. A diagnosis of breast cancer was determined for subjects assigned the code for malignant breast cancer (C50 in the Korean Standard Classification of Diseases) and that for cancer special cases (V193). Therefore, the date of diagnosis of breast cancer was defined as that of the first claim for a code of V193 and C50.

\subsection{Indicators}

The participation rate, positivity rate, positive predictive value (PPV), and detection rate of breast cancer screening were evaluated.

\subsubsection{Participation Rate of Screening for Breast Cancer}

The participation rate of screening for breast cancer was defined as the number of breast cancer screening participants who underwent mammography for breast cancer during a particular year per 100 of all women over 40 years old of breast cancer screening subjects.

$$
\text { Participation rate }=\frac{\text { Breast cancer screening participants }}{\text { Breast cancer screening subjects }} \times 100
$$

\subsubsection{Positivity Rate of Screening for Breast Cancer}

The positivity rate of screening for breast cancer was defined as the number of positive tests per 100 breast cancer screening participants.

$$
\text { Positivity rate }=\frac{\text { Tested positive }}{\text { Breast cancer screening participants }} \times 100
$$

\subsubsection{PPV of Screening for Breast Cancer}

The PPV is the proportion of subjects diagnosed with a disease among those who tested positive for that disease. In this study, the PPV was defined as patients with insurance claims (C50 + V193) for breast cancer codes within 180 days of screening notification among those with positive results of breast cancer screening per 1000 who tested positive.

$$
\mathrm{PPV}=\frac{\text { Detected breast cancer }(\mathrm{C} 50+\mathrm{V} 193) \text { within } 180 \text { days }}{\text { Tested positive }} \times 1000
$$

\subsubsection{Detection Rate of Screening for Breast Cancer}

Among the participants in breast cancer screening, the definition was detection by breast cancer screening if treatment for breast cancer (C50 + V193) occurred within 180 days from the notification date of the breast cancer screening result. Thus, the detection rate of screening for breast cancer was defined as the number of participants in breast cancer screening who tested positive for breast cancer and were treated within 180 days of their notification date per 1000 breast cancer screening participants.

$$
\text { Detection rate }=\frac{\text { Tested positive and breast cancer detected }(\mathrm{C} 50+\mathrm{V} 193) \text { within } 180 \text { days }}{\text { Breast cancer screening participants }} \times 1000
$$

To compare the detection rate of the breast cancer screening program with the incidence rate from KCCR of the 40-69 year age group and $\geq 70$ year age group, the detection rate and incidence rate were standardized with the 2009 population in Korea.

Age-standardized detection rate. Females $>40$ years of age in 2009 who participated in breast cancer screening were defined as the standardized population for calculation of the annual age-standardized detection rate of breast cancer (unit, 10 years).

$$
\text { Age }- \text { standardized detection rate }=\sum \frac{\text { Detection rate for age group } \times \text { standardized population for age group }}{\text { Standardized population }}
$$


Age-standardized incidence rate. The age-standardized incidence rate of breast cancer according to the KCCR after 2009 (unit, 10 years) was calculated using the number of women $>40$ years of age in the middle of 2009 according to the National Statistics Office as the standardized population.

Age - standardized incidence rate $=\sum \frac{\text { Incidence rate for age group } \times \text { standardized population for age group }}{\text { Standardized population }}$

\subsection{Statistical Analyses}

SAS (ver. 9.1; SAS Institute, Cary, NC, USA) statistical software and Microsoft Excel (ver. 2013, Microsoft, Redmond, WA, USA) were used for data analysis. The significance of differences in the PPV and the rate of detection of breast cancer between the two groups was evaluated by calculating the $95 \%$ confidence internal (CI).

\subsection{Ethics Statement}

This study used secondary data provided by the National Health Insurance Service (NHIS-2019-1-115) and was exempted from review by the Institutional Review Board of Konkuk University because no personal information was analyzed (approval number: 7001355-201901-E-086).

\section{Results}

\subsection{Subjects and Participants; and Rates of Participation, Positivity}

In the 40-69 year age group, the number of subjects and participants in breast cancer screening and the rate of participation fluctuated from 2009 to 2016 (Table 1). Similarly, in the $\geq 70$ year age group, the number of subjects and participants in breast cancer screening and the rate of participation fluctuated from 2009 to 2016; however, the number of participants increased annually after 2009 (Table 1). The participation rate increased from $52.3 \%$ in 2009 to $67.7 \%$ in 2016 in the $40-69$ year age group and increased from $39.8 \%$ to $51.6 \%$ in the $\geq 70$ year age group. The rate of participation in the $\geq 70$ year age group was lower than that in the 40-69 year age group from 2009 to 2016 . The positivity rate of screening test in the 40-69 year age group decreased from $18.7 \%$ in 2009 to $15.2 \%$ in 2016 and that in the $\geq 70$ year age group increased from $5.9 \%$ in 2009 to $8.0 \%$ in 2016 .

Table 1. Numbers of subjects and participants and rates of participation and positivity, 2009 to 2016.

\begin{tabular}{cccccccccc}
\hline & & $\mathbf{2 0 0 9}$ & $\mathbf{2 0 1 0}$ & $\mathbf{2 0 1 1}$ & $\mathbf{2 0 1 2}$ & $\mathbf{2 0 1 3}$ & $\mathbf{2 0 1 4}$ & $\mathbf{2 0 1 5}$ & $\mathbf{2 0 1 6}$ \\
\hline \multirow{2}{*}{ Subjects for } & $40-69$ & $4,963,914$ & $4,482,903$ & $5,171,907$ & $4,563,574$ & $4,713,451$ & $4,765,409$ & $4,945,719$ & $5,072,341$ \\
Screening & $\geq 70$ & 948,517 & 918,220 & $1,129,966$ & $1,012,101$ & $1,049,574$ & $1,083,725$ & $1,111,346$ & $1,175,298$ \\
& Total & $5,912,431$ & $5,401,123$ & $6,301,873$ & $5,575,675$ & $5,763,025$ & $5,849,134$ & $6,057,065$ & $6,247,639$ \\
\hline \multirow{3}{*}{ Participants } & $40-69$ & $2,597,693$ & $2,525,167$ & $2,909,618$ & $2,858,449$ & $2,918,093$ & $3,031,223$ & $3,222,881$ & $3,432,426$ \\
& $\geq 70$ & 377,662 & 381,887 & 458,570 & 483,923 & 497,824 & 538,924 & 551,969 & 606,112 \\
& Total & $2,975,355$ & $2,907,054$ & $3,368,188$ & $3,342,372$ & $3,415,917$ & $3,570,147$ & $3,774,850$ & $4,038,538$ \\
\hline \multirow{2}{*}{ Participation } & $40-69$ & 52.3 & 56.3 & 56.3 & 62.6 & 61.9 & 63.6 & 65.2 & 67.7 \\
Rate (\%) & $\geq 70$ & 39.8 & 41.6 & 40.6 & 47.8 & 47.4 & 49.7 & 49.7 & 51.6 \\
& Total & 50.3 & 53.8 & 53.4 & 59.9 & 59.3 & 61 & 62.3 & 64.6 \\
\hline \multirow{2}{*}{ Positivity } & $40-69$ & 18.7 & 16.3 & 15.7 & 15.9 & 15.6 & 16.1 & 15.7 & 15.2 \\
Rate (\%) & $\geq 70$ & 5.9 & 6.2 & 6.8 & 7.0 & 7.7 & 7.8 & 8.0 & 8.0 \\
& Total & 17.0 & 15.0 & 14.5 & 14.6 & 14.5 & 14.9 & 14.6 & 14.2 \\
\hline
\end{tabular}

\subsection{PPV and Detection Rate}

The PPV of the $\geq 70$ year age group was significantly higher than that of the 40-69 year age group from 2009 to 2016 (Figure 1). The PPV of both groups increased for 2009 to 2016, 40-69 year age group, 5.7 to 10.9 (95\% CI, 5.48-5.90 to $10.36-11.46$ ); $\geq 70$ year age group, 11.1 to 17.3 (95\% CI, $9.72-12.47$ to 16.47-18.21). 


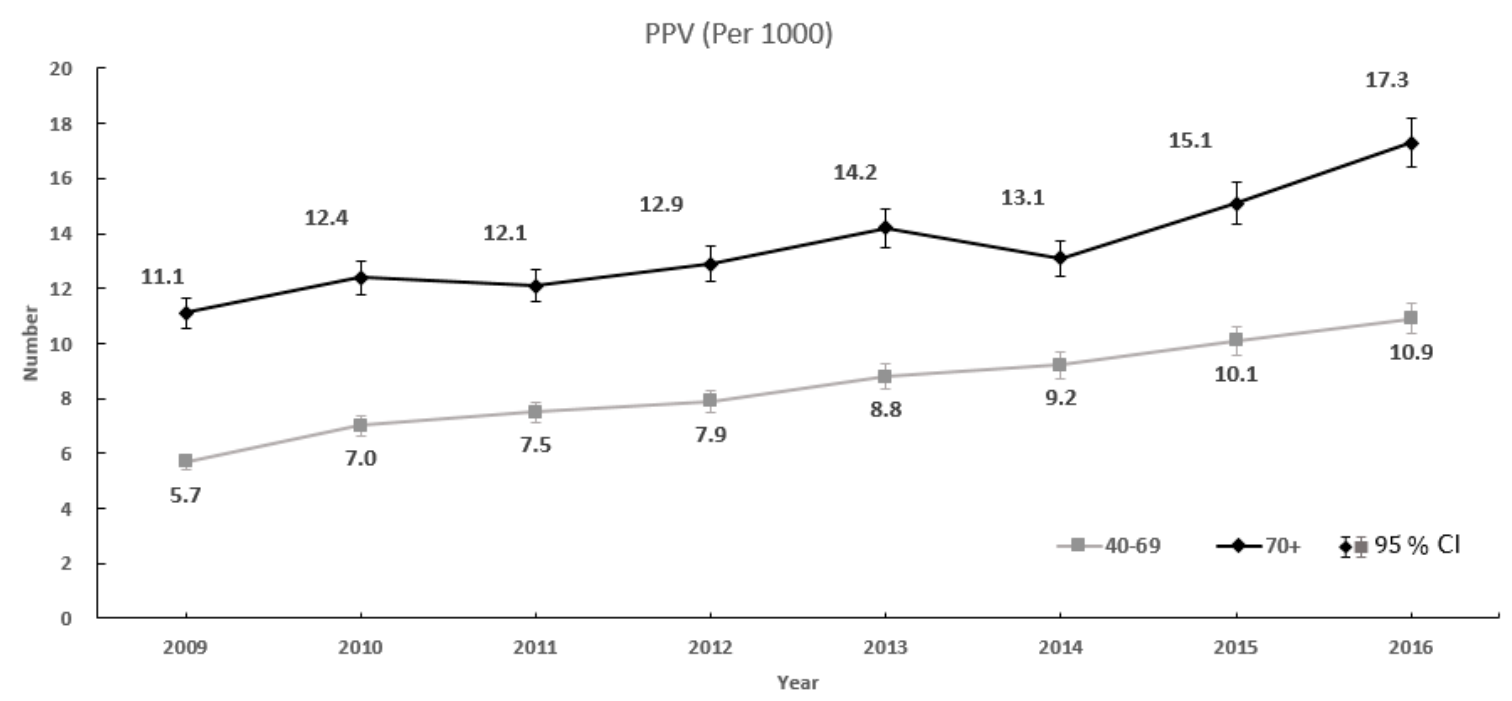

Figure 1. PPV of breast cancer screening by age group, 2009 to 2016.

The detection rate of breast cancer in the group increased from 1.06 (95\% CI, 1.01-1.11) in 2009 to 1.66 (95\% CI, 1.58-1.75) in 2016 (Figure 2). The rate of detection in the $\geq 70$ year age group increased from 0.66 (95\% CI, 0.62-0.71) in 2009 to 1.38 (95\% CI, 1.31-1.44) in 2016. The rate of detection of breast cancer in the $\geq 70$ year age group was lower than that in the 40-69 year age group throughout the study period.

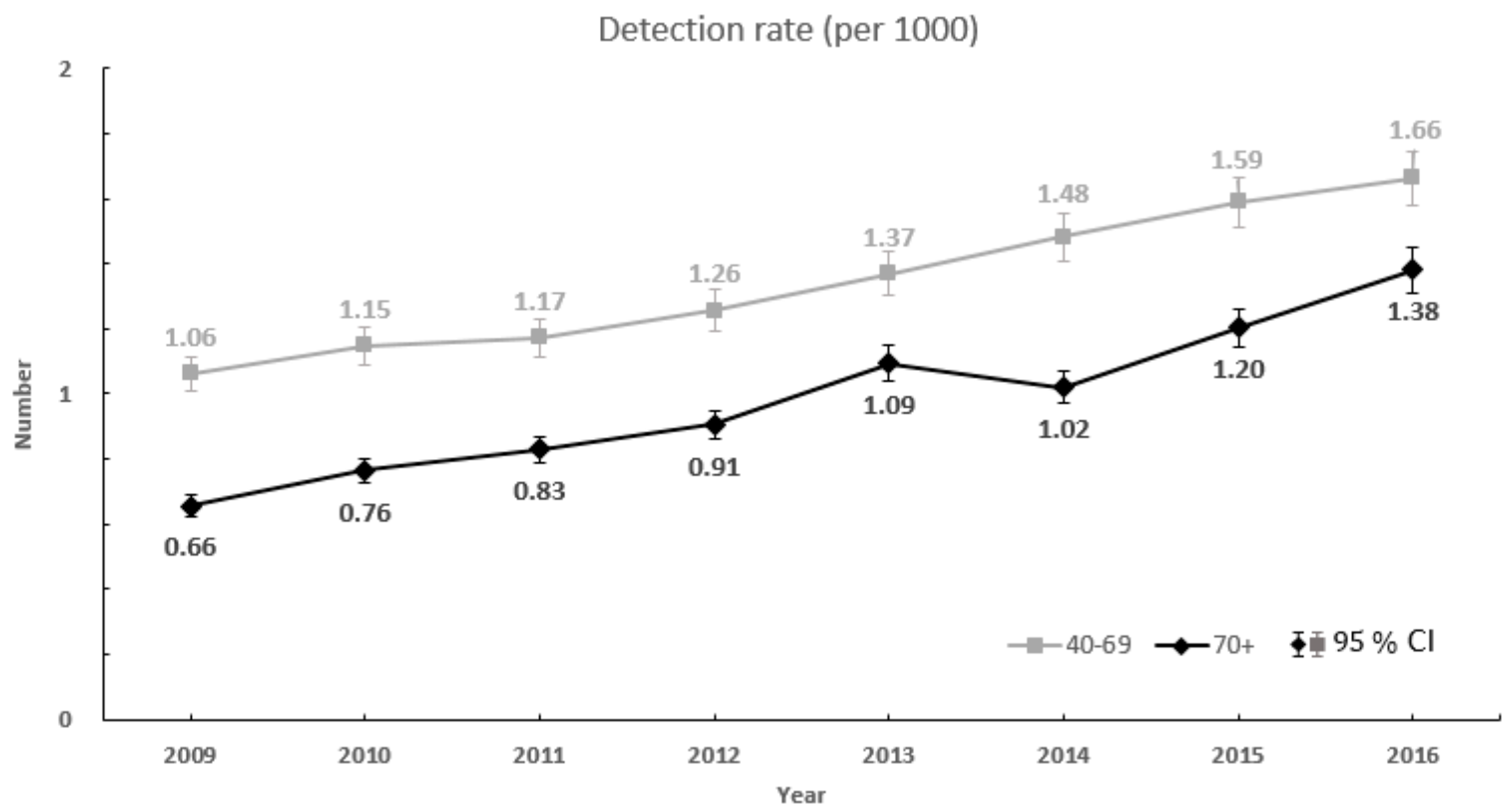

Figure 2. Detection rate of breast cancer by age group, 2009 to 2016.

\subsection{Comparison Age-Standardized Detection Rate with Age-Standardized Incidence Rate}

In the 40-69 year age group, the NHIS's age-standardized detection rate of breast cancer increased annually from 106.1 in 2009 to 158.6 in 2015, and did not differ from the KCCR's age-standardized incidence rate (Figure $3 \mathrm{~A})$.

In the $\geq 70$ year age group, the NHIS's age-standardized detection rate of breast cancer increased annually from 65.7 in 2009 to 120.3 in 2015, and was 1.9 to 2.7 fold of the KCCR's age-standardized incidence rate of breast cancer (Figure 3B). 
(A) 40-69 Age standardization Rates (100000)

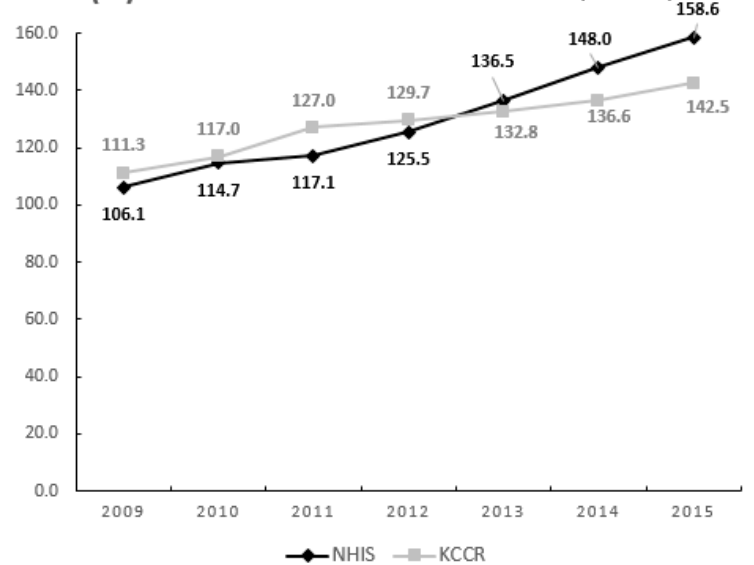

(B) 70+ AGE STANDARDIZATION RATES (100000)

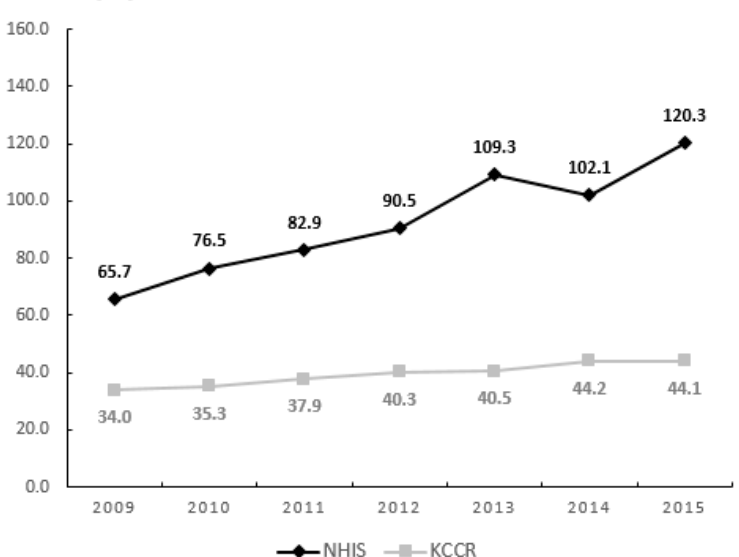

Figure 3. Age-standardized NHIS (detection rate) and KCCR (incidence rate) of breast cancer, 2009 to 2016. (A) 40-69 years of age, NHIS vs. KCCR; (B) $\geq 70$ years of age, NHIS vs. KCCR. NHIS, National Health Insurance Service; KCCR, Korea Central Cancer Registry.

\section{Discussion}

The purpose of this study was to present the differences in epidemiological characteristics on a breast cancer screening program between the 40-69 year age group and the $\geq 70$ year age group. The number of subjects and participants in breast cancer screening in the $\geq 70$ year age group increased. This is probably due to the increased number of participants from the aging population and expanded average lifespan.

Participation rates in breast cancer screening increased from 2009 to 2016 in both age groups, reflecting the ongoing publicity of the need and importance of cancer screening along with the need for public health [18]. In addition, the age group over 70 showed a lower participation rate than the 40-69 group, which is likely to be due to the lower susceptibility to, and severity of breast cancer in patients at the age of $\geq 70$ [19].

The positivity rate in the 40-69 age group was higher than that in the $\geq 70$ age group, which is likely to be due to the higher incidence of breast cancer in the former [17]. The positivity rate in the $\geq 70$ age group increased annually during the study period. This suggests that the incidence of breast cancer among $>70$ aged women is increasing, in agreement with the Korean cancer statistics [20]. Also, the positivity rate in this study was much higher than the recall rate in Western countries [21]. The reason might be as follows: The high sensitivity of mammography as a screening method was emphasized so as not to miss the cancer cases in Korea while the threat of litigation against malpractice could cause a tendency of testing positive.

The PPV for breast cancer of the $\geq 70$ age group increased over time and was higher than that of the 40-69 age group. The PPV was affected by the prevalence of breast cancer, sensitivity, and specificity of the screening tool [17]. The higher PPV in the age group of 70 and older indicates that breast cancer screening is still effective in women aged over 70. Since the breast density affects the accuracy of mammography [22], the PPV of the $\geq 70$ age group with low breast density [23] might be high. The relatively lower PPV in the young group in this study could be explained by low prevalence of breast cancer and higher positivity rate of screening.

The detection rate of breast cancer per 1000 in the $\geq 70$ year age group increased annually after 2009. This is similar to the case in the United Kingdom, where the number of women at the age of $>73$ diagnosed with breast cancer has increased consistently [24]. In addition, the age-standardized breast cancer detection rate was higher among women aged 40-69 than women aged 70 or older. However, in the age group of 70 or older, the NHIS's age-standardized breast cancer detection rate was significantly higher than that of the KCCR's age-standardized breast cancer incidence rate from 2009 to 2015 . This means that breast cancer for the age group over 70 is likely to be diagnosed by a 
breast cancer screening program, not by self-examination or symptoms [19]. This is consistent with a report that screening is beneficial for older women for whom mammography has high sensitivity and specificity, and who have a high rate of detection along with PPV for breast cancer, low rates of retesting, and false positives [25]. Breast cancer has become a potentially curable disease with the development of new therapies over the past two decades [26]. Therefore, early detection is the most important way to avoid the development and progression of breast cancers regardless of age.

To set the upper age limit for breast cancer screening, all-cause mortality, cancer specific mortality and stage shift are generally considered [6]. Although stage shifts or mortality rate were not evaluated in this study, it does show that the NHIS's age-standardized breast cancer detection rate due to breast cancer screening was 1.9 to 2.7 fold of the KCCR's age-standardized breast cancer incidence rate in the age group of 70 or older. Finally, the question of whether the upper age limit of screening should be increased, and to what level, is therefore of great importance in the drive to improve cancer outcomes in older women. One of the key arguments in favor of extending the upper age limit of screening is the increasing life expectancy of Western populations [21].

Because the data of this study used the whole data of breast cancer screening and the whole data of claims for breast cancer, the effect of breast cancer screening such as detection rate could be evaluated. However, there is no formal guideline for monitoring breast screening program performance in Korea. Especially, the interval cancer of breast cancer has increased 41.8 in 2009 to 58.5 in 2014 among 100,000 negative screening participants [17]. In addition to the researchers' effort, the relevant indices about breast cancer screening have to be reported systemically and continuously by the NHIS who manage the two databases. There are many ways to detect breast cancer apart from the screening test, such as showing symptoms, regular check on exposing to risk factors like hormone treatment etc. However, we tried here to evaluate the effect of breast cancer screening only using a short detection time (six months) after screening.

\section{Conclusions}

The comparison between the age-standardized detection rate of breast cancer from the data of NHIS and the age-standardized incidence rate of breast cancer from KCCR showed that the early detection effect of breast cancer screening was greater in women over 70 years old. Further studies on cost effectiveness, mortality rate, and stage shifts are needed to set the upper age limit for breast cancer screening.

Author Contributions: Conceptualization, M.K. and H.K.; data curation, H.C.; formal analysis, M.K. and H.K.; methodology, T.-H.H., S.K. and M.S.; resources, K.-S.L., T.-H.H. and S.K.; supervision, T.-H.H. and K.-S.L.; visualization, S.K. and M.S.; writing-original draft preparation, M.K. and H.C.; writing-review and editing, M.K., H.K. and H.C. All authors have read and agreed to the published version of the manuscript.

Funding: This research received no external funding.

Acknowledgments: The authors thank the NHIS for permission to use NHIS data (NHIS-2019-1-115).

Conflicts of Interest: The authors declare no conflict of interest.

\section{References}

1. Ferlay, J.; Soerjomataram, I.; Dikshit, R.; Eser, S.; Mathers, C.; Rebelo, M.; Parkin, D.M.; Forman, D.; Bray, F. Cancer incidence and mortality worldwide: Sources, methods and major patterns in GLOBOCAN 2012. Int. J. Cancer 2015, 136, E359-E386. [CrossRef] [PubMed]

2. Park, S.K. Epidemiological characteristics of breast cancer in Koreans. J. Korean. Med. Assoc. 2019, 62, 424-436. [CrossRef]

3. National Cancer Information Center, Ministry of Health and Welfare. Available online: https://www.cancer. go.kr/lay1/S1T639C643/contents.do (accessed on 25 October 2018). 
4. Ministry of Health and Welfare. Cancer Registration Statistics. Available online: http: //kosis.kr/statHtml/statHtml.do?orgId=117\&tblId=DT_117N_A00022\&vw_cd=MT_ZTITLE\&list_id=101_ $11744 \&$ seqNo=\&lang_mode=ko\&language=kor\&obj_var_id=\&itm_id=\&conn_path=MT_ZTITLE (accessed on 22 January 2020).

5. Ministry of Health and Welfare. Cancer Registration Statistics. Available online: http://kosis.kr/statHtml/ statHtml.do?orgId=117\&tblId=DT_117N_A00023\&conn_path=I2 (accessed on 25 October 2018).

6. Cancer Facts \& Figures 2017. Available online: https://www.cancer.org/content/dam/cancer-org/research/ cancer-facts-and-statistics/annual-cancer-facts-and-figures/2017/cancer-facts-and-figures-2017.pdf (accessed on 25 October 2018).

7. Lee, J.H.; Yim, S.H.; Won, Y.J.; Jung, K.W.; Son, B.H.; Lee, H.D.; Lee, E.S.; Yoo, K.Y.; Ahn, S.H.; Shin, H.R. Population-based breast cancer statistics in Korea during 1993-2002: Incidence, mortality, and survival. J. Korean Med. Sci. 2007, 22, 11-16. [CrossRef] [PubMed]

8. Lee, K.S.; Chang, H.S.; Lee, S.M.; Park, E.C. Economic burden of cancer in Korea during 2000-2010. Cancer Res. Treat. 2015, 47, 387-398. [CrossRef]

9. Lee, E.H.; Park, B.; Kim, N.S.; Seo, H.J.; Ko, K.L.; Min, J.W.; Shin, M.H.; Lee, K.; Lee, S.; Choi, N.; et al. The Korean guideline for breast cancer screening. J. Korean Med. Assoc. 2015, 58, 408-419. [CrossRef]

10. Smith, R.A. The value of modern mammography screening in the control of breast cancer: Understanding the underpinnings of the current debates. Cancer Epidemiol. Biomarkers Prev. 2014, 23, 1139-1146. [CrossRef]

11. Pace, L.E.; Keating, N.L. A systematic assessment of benefits and risks to guide breast cancer screening decisions. JAMA 2014, 311, 1327-1335. [CrossRef]

12. Shah, T.A.; Guraya, S.S. Breast cancer screening programs: Review of merits, demerits, and recent recommendations practiced across the world. J. Microsc. Ultrastruct. 2017, 5, 59-69. [CrossRef]

13. U.S. Preventive Services Task Force. Screening for Breast Cancer: U.S. Preventive Services Task Force Recommendation Statement. Ann. Intern. Med. 2016, 164, 279-296. [CrossRef]

14. Tonelli, M.; Connor, G.S.; Joffres, M.; Dickinson, J.; Singh, H.; Lewin, G.; Birtwhistle, R.; Fitzpatrick-Lewis, D.; Hodgson, N.; Ciliska, D.; et al. Recommendations on screening for breast cancer in average-risk women aged 40-74 years. Can. Med. Assoc. J. 2011, 183, 2147. [CrossRef]

15. Hamashima, C.C.; Hattori, M.; Honjo, S.; Kasahara, Y.; Katayama, T.; Nakai, M.; Nakayama, T.; Morita, T.; Ohta, K.; Ohnuki, K.; et al. The Japanese Guidelines for Breast Cancer Screening. Jpn. J. Clin. Oncol. 2016, 46, 482-492. [CrossRef] [PubMed]

16. Evaluation of the Validity of Current National Health Screening Program and Plan to Improve the System. Available online: https://www.scienceopen.com/document?vid=d0b8c597-fce9-49cc-8084-da4a94358dd2 (accessed on 11 May 2020).

17. Lee, K.; Kim, H.; Lee, J.H.; Jeong, H.; Shin, S.A.; Han, T.; Seo, Y.L.; Yoo, Y.; Nam, S.E.; Park, J.H.; et al. Retrospective observation on contribution and limitations of screening for breast cancer with mammography in Korea: Detection rate of breast cancer and incidence rate of interval cancer of the breast. BMC Women's Health 2016, 16, 72. [CrossRef] [PubMed]

18. Lee, S.Y.; Jeong, S.H.; Kim, J.; Jung, S.H.; Song, K.B.; Nam, C.M. Scheduling mammography screening for the early detection of breast cancer in Korean women. J. Med. Screen. 2007, 14, 205-209. [CrossRef] [PubMed]

19. Michielutte, R.; Sharp, P.C.; Foley, K.L.; Cunningham, L.E.; Spangler, J.G.; Paskett, E.D.; Case, L.D. Intervention to increase screening mammography among women 65 and older, Health Education Research. Health Educ. Res. 2005, 20, 149-162. [CrossRef]

20. Jung, K.W.; Won, Y.J.; Kong, H.J.; Lee, E.S.; Community of Population-Based Regional Cancer Registries. Cancer Statistics in Korea: Incidence, Mortality, Survival, and Prevalence in 2015. Cancer Res. Treat. Off. J. Korean Cancer Assoc. 2018, 50, 303-316. [CrossRef]

21. Domingo, L.; Hofvind, S.; Hubbard, R.A.; Román, M.; Benkeser, D.; Sala, M.; Castells, X. Cross-national comparison of screening mammography accuracy measures in U.S., Norway, and Spain. Eur. Radiol. 2016, 26, 2520-2528. [CrossRef]

22. Lehman, C.; White, E.; Peacock, S.; Drucker, M.; Urban, N. Effect of age and breast density on screening mammograms with false-positive findings. AJR Am. J. Roentgenol. 1999, 173, 1651-1655. [CrossRef]

23. Checka, C.M.; Chun, J.E.; Schnabel, F.R.; Lee, J.; Toth, H. The Relationship of Mammographic Density and Age: Implications for Breast Cancer Screening. AJR Am. J. Roentgenol. 2012, 198, W292-W295. [CrossRef] 
24. Rafia, R.; Brennan, A.; Madan, J.; Collins, K.; Reed, M.W.; Lawrence, G.; Robinson, T.; Greenberg, D.; Wyld, L. Modeling the Cost-Effectiveness of Alternative Upper Age Limits for Breast Cancer Screening in England and Wales. Value Health 2016, 19, 404-412. [CrossRef]

25. Cindy, S.L.; Linda, M.; Bonnie, N.J.; Edward, A.S.; Bethany, L.N. Screening for Breast Cancer in Women Age 75 Years and Older. AJR Am. J. Roentgenol. 2018, 210, 256-263. [CrossRef]

26. Ng, Z.X.; Ong, M.S.; Jegadeesan, T.; Deng, S.; Yap, C.T. Breast Cancer: Exploring the Facts and Holistic Needs during and beyond Treatment. Healthcare 2017, 5, 26. [CrossRef] [PubMed]

(C) 2020 by the authors. Licensee MDPI, Basel, Switzerland. This article is an open access article distributed under the terms and conditions of the Creative Commons Attribution (CC BY) license (http://creativecommons.org/licenses/by/4.0/). 